\title{
Overview and problems of BIM implementation in Japan
}

(C) The Author(s) 2017. Published by Higher Education Press. This is an open access article under the CC BY license (http:// creativecommons.org/licenses/by/4.0)

\begin{abstract}
This paper aims to overview Building Information Modeling (BIM) implementation and problems of BIM implementation in Japan. First, BIM implementation guidelines and pilot projects are introduced. Then, some popular BIM software together with typical implementation cases are provided. BIM implementation in Japan is not always encouraged via a top-down consensus in architectural firms and general contractors, as the client and architects can reduce the project risk inherent in design and drawings by transferring these tasks to a general contractor. The paper finally discusses the problems in project management to present a strategy to develop a new version of BIM that will provide value to all of the stakeholders of a project.
\end{abstract}

Keywords Building Information Modeling, general contractor, architect, drawing, procurement, project management

\section{Introduction}

This paper aims to overview Building Information Modeling (BIM) implementation and elaborate upon the problems with BIM in Japan. BIM implementation in Japan is not always encouraged with a top-down consensus in architectural firms and general contractors, as the client is often not aware of the value and incentive to introduce BIM use into the contracts of the project. Japanese general contractors have the ability to produce and coordinate architectural drawings and shop drawings by hiring inhouse architects and engineers. The client and the architects can reduce the project risk inherent in design and drawings by transferring it to the general contractor, so

Received January 17, 2017; accepted April 24, 2017

Takashi KANETA ( $($ ), Shuzo FURUSAKA, Nisi DENG

Department of Architecture and Architectural Engineering, Graduate School of Engineering, Kyoto University, Kyoto 615-8540, Japan

E-mail: kaneta@archi.kyoto-u.ac.jp they are not sensitive to the schedule decision making in the project process and do not have a need to introduce BIM.

The hot topics of BIM, e.g., implementation guidelines and pilot projects operated by MLIT (Ministry of Land, Infrastructure, Transport and Tourism) and other public sector agencies, are introduced first. Then, the names of BIM software popular in Japan and their vendors are provided as well as typical cases of their implementation in a large architectural firm and major general contractor in Japan. The authors also review past research, such as on product modeling, integrated information systems for design and construction, and other original systems. The authors finally discuss the problems of project management to present a strategy to develop a new version of BIM that can provide value to all of the stakeholders of a project.

\section{Topics of BIM in Japan}

2.1 Policy of the Ministry of Land, Infrastructure, Transport and Tourism

\subsubsection{BIM guidelines}

The Government Buildings Department (GBD) of the Ministry of Land, Infrastructure, Transport and Tourism (MLIT) published "Guideline for BIM Application in Public Building Projects (The Ministry of Land, Infrastructure, Transport and Tourism, 2014)" in March 2014 to present the fundamental concepts in creating and using a building information model for the architects and contractors of government building projects. It is regarded as the only official guideline by the Government of Japan. In this guideline, the purpose of the use of BIM is clarified, and concrete examples of engineering issues are shown. Typical examples of modeling are also illustrated, and Levels of Development (LOD) are specified. It is expected that this guideline will make it efficient for architects and contractors to introduce BIM. 


\subsubsection{BIM implementation project}

Prior to this, GBD prepared to conduct design. GBD selected pilot projects for government buildings to implement BIM for design in 2010 (Government Building Department, 2014a, 2014b, 2014c, 2014d). Specifically, the following 3 projects are known as BIM implementation projects.

- Shinjuku Labors Federal Office Building (Government Building Department, 2014b)

- Shizuoka Regional Legal Office Fujieda Branch (Government Building Department, 2014c)

- Maebashi Regional Federal Office Building (Government Building Department, 2014d)

The Shinjuku Labors Federal Office Building (Fig.1) is the first project of the trial of BIM implementation in government office buildings. The total floor area is approximately 3500 square meters, making it a moderate-sized government office building. BIM was used from the early stage of the design.

The Shizuoka Regional Legal Office Fujieda Branch (Fig. 2) is built in a residential area. The effect of BIM implementation was evaluated in this project.

The Maebashi Regional Federal Office Building (Fig.3) is the largest government office building among the BIM implementation projects. There are 9 government offices inside of this building. This project was finished in May 2015.

\subsection{Other public projects}

\subsubsection{BIM implementation by the Ministry of Justice}

The Ministry of Justice (MOJ) operates prisons and other facilities. It is necessary for these facilities to restrict communication and visibility between the inmates and external areas and to prevent accidents, such as inmate escapes. BIM was implemented in a junior prison project in the design phase. The in-house architects $\&$ engineers of MOJ collaborated with the prison staff and security guards to verify the visibility and the blind spots of the facility using the viewer of BIM.

\subsubsection{Local government project}

The "New Sukagawa City Hall", located in Fukushima Prefecture, is an example of a BIM implementation project by a local government ${ }^{1)}$ (Fig.4). AXS Satow, Inc., won the design proposal. The engineer of Satow said, "As a condition of the design contract, Sukagawa City asked us to use BIM as an advanced case of a building project to provide high accuracy and consistency in architectural design as well as to share the design contents with public citizens. Of course, BIM was implemented not only during the design phase but also in the construction phase and after the completion for facility management ${ }^{2}$.

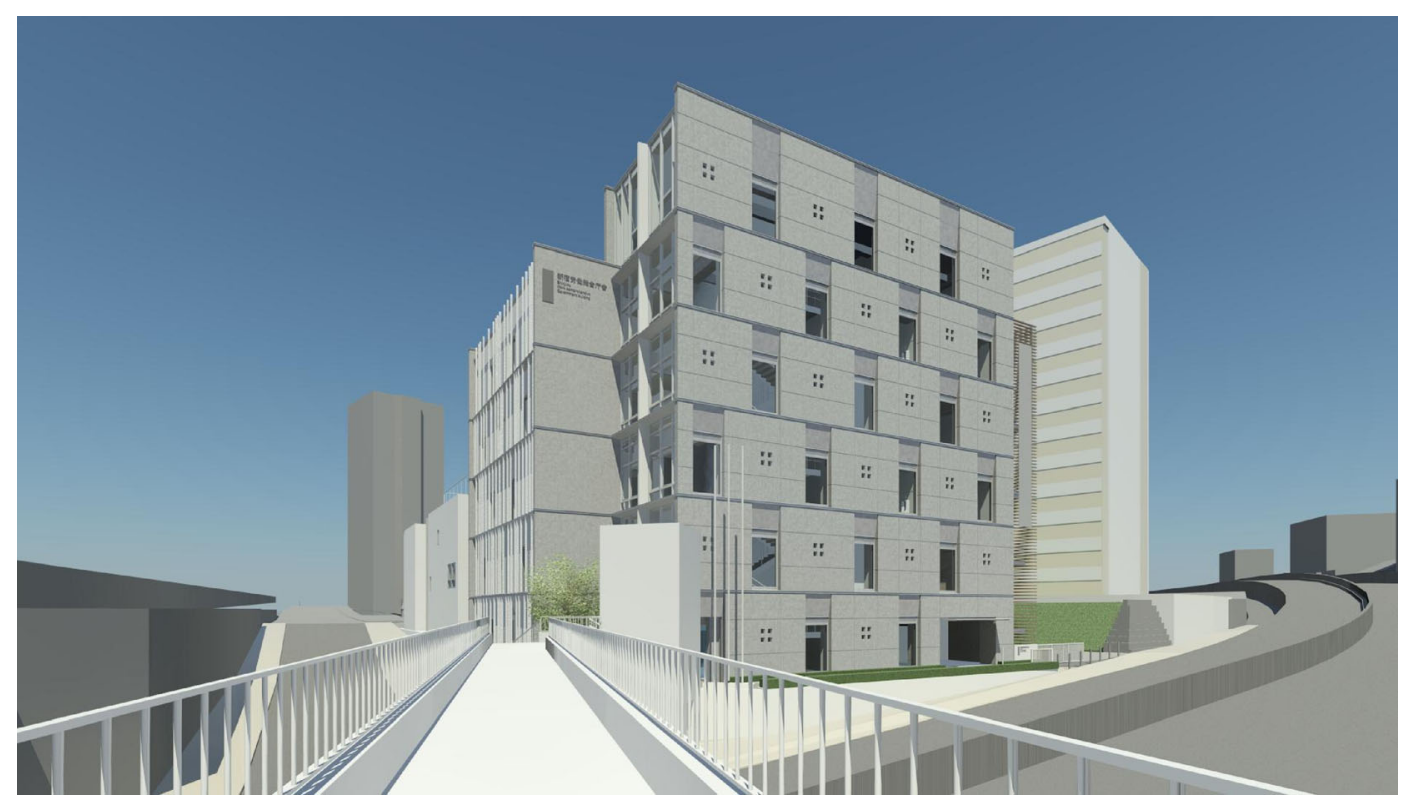

Fig. 1 Shinjuku Labors Federal Office Building (Government Building Department, 2014b)

1) Sukagawa City Government Website. Information about New City Hall Project. http://www.city.sukagawa.Fukushima.jp/3417.htm

2) Autodesk user's report AXS Satow Inc. http://bim-design.com/catalog/img/ad_satosogo_p1_low.pdf, 2015 


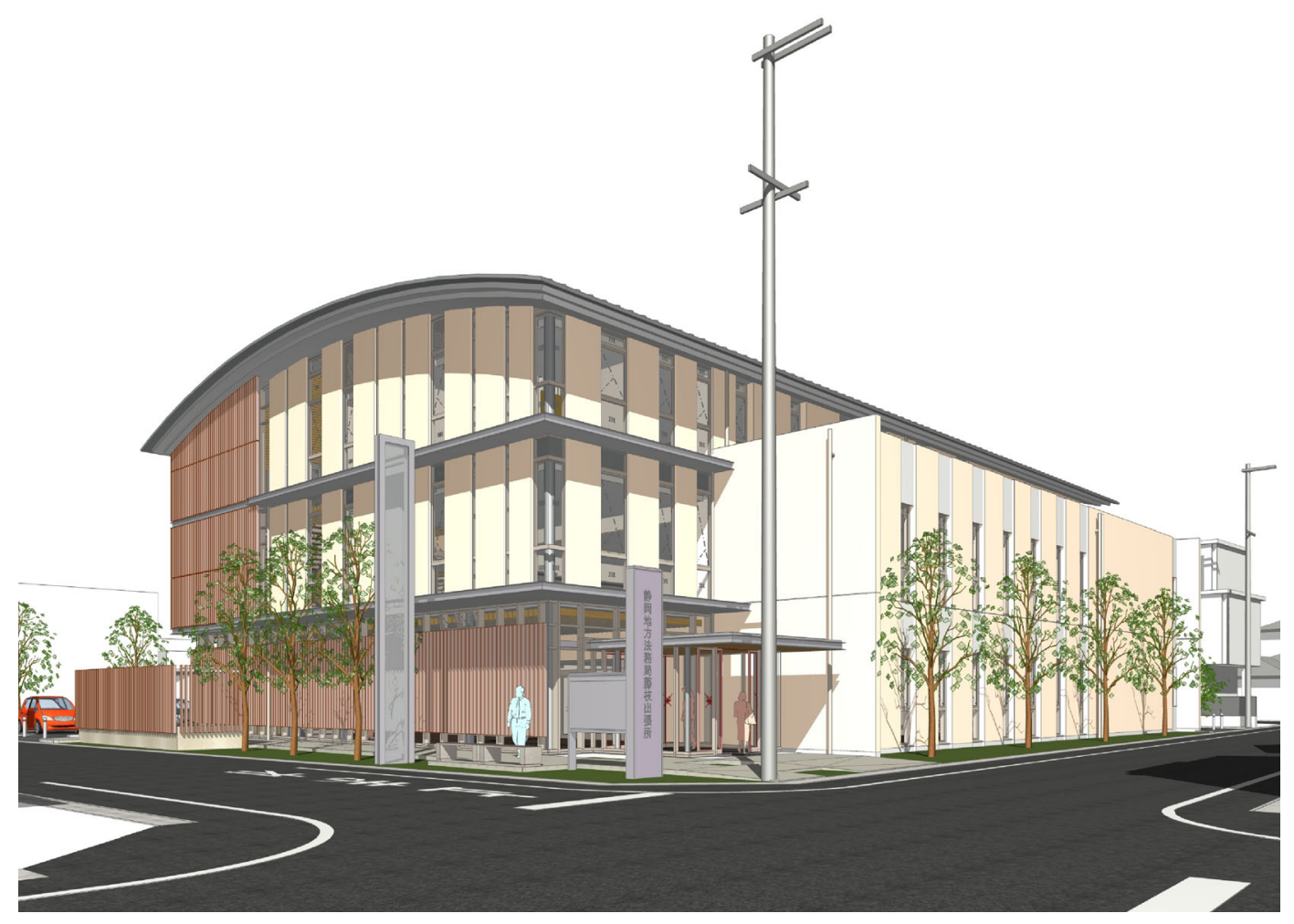

Fig. 2 Shizuoka Regional Legal Office Fujieda Branch (Government Building Department, 2014c)

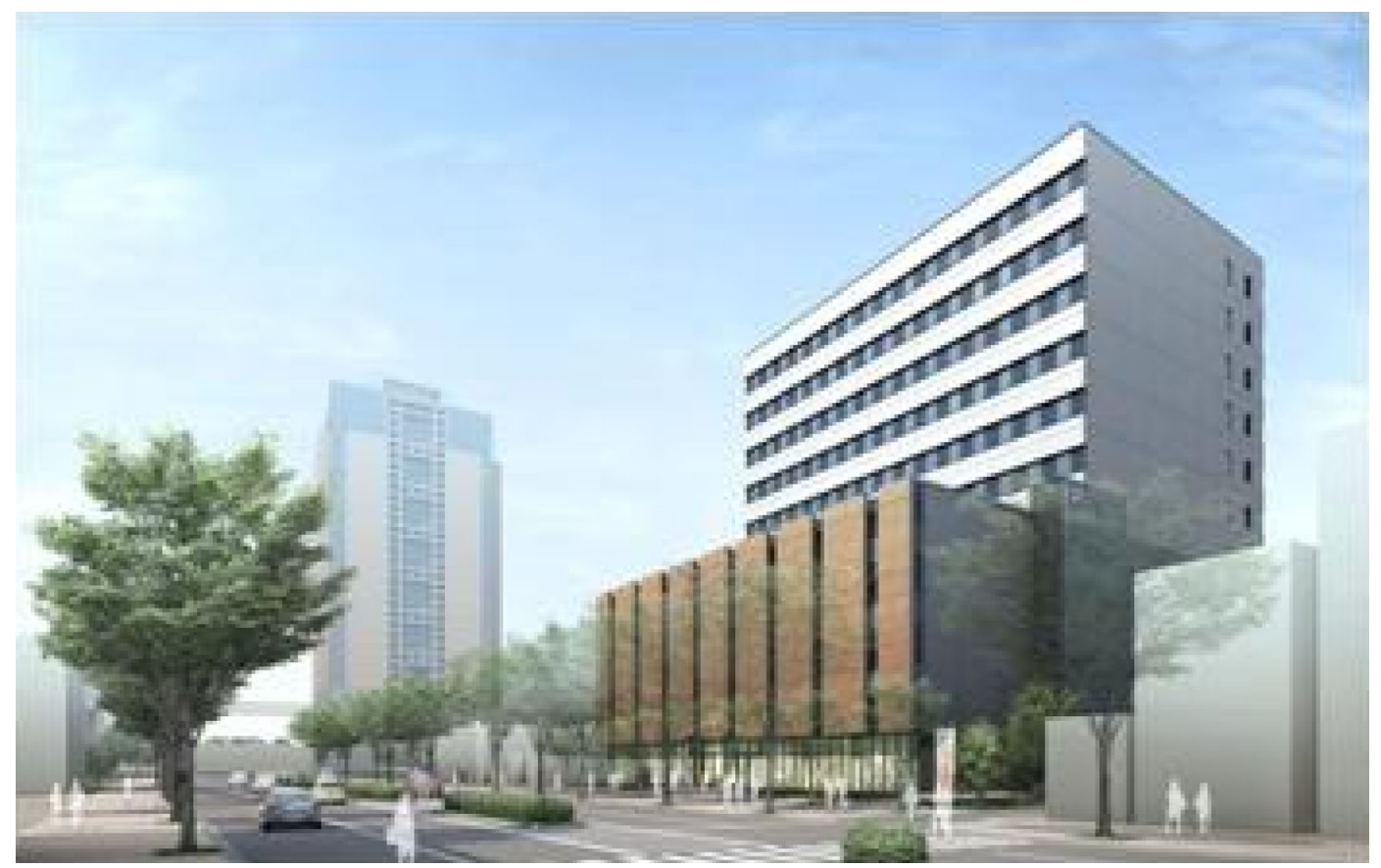

Fig. 3 Maebashi Regional Federal Office (Building Government Building Department, 2014d) 


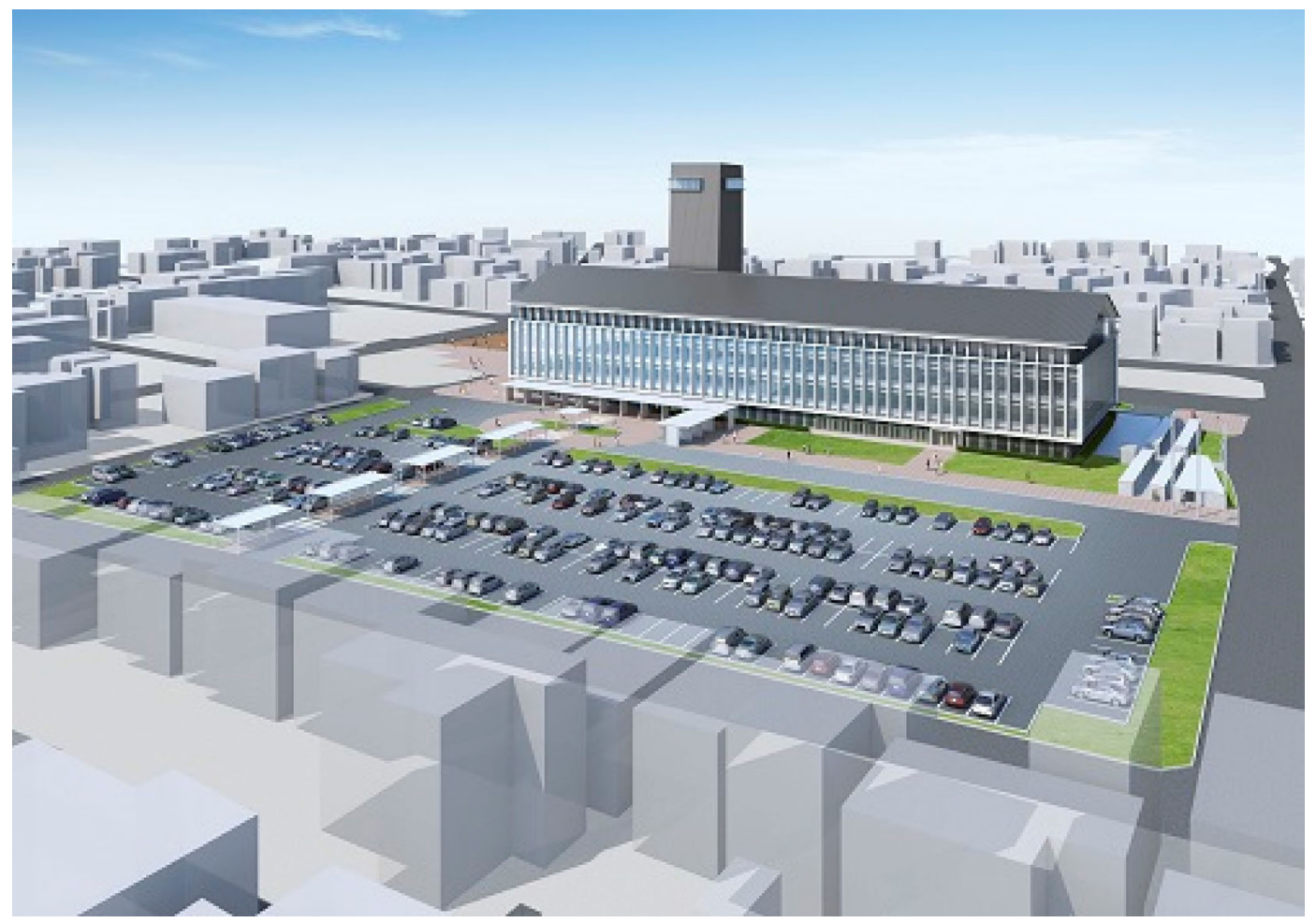

Fig. 4 New Sukagawa City Hall (http://www.city.sukagawa.fukushima.jp/6220.htm)

The concept design of this project started in November 2012, and the development design ended in March 2014. Construction was started in autumn of 2014, and it was planned to be finished in March 2015 but delayed to March 2017. This was because of the complex construction plan of the mixed structure and the procurement of the labor and materials ${ }^{1)}$.

\subsection{Activities of institutions}

Academic presentations and papers containing "BIM" as a keyword have been frequently found in Japan since the year 2009, which is sometimes called the 1st Year of BIM in Japan. For example, a "BIM Day Symposium" was held in February 2015 and 2016 by the Research Committee on Information Systems Technology, the Architectural Institute of Japan (AIJ). More than 150 participants were enrolled in these symposia each time, and all of the seats were fully booked. In these symposia, the future paradigm of BIM was discussed, which encouraged people to think about BIM. However, there were few tangible success stories reported and no feedback from the engineers and managers who operate actual projects (especially building construction sites).

The Japanese Chapter of building SMART, formerly the International Alliance for Interoperability (IAI) Japan, is active in the standard coding of BIM. The Japan Federation of Construction Contractors, the top organization of major general contractors, and the Building Surveyor's Institute of JAPAN (BSIJ) also actively conduct events and disseminate information on BIM.

\section{BIM implementation in Japan}

\subsection{BIM software commonly used in Japan}

There are differences in the development and the use of BIM software in Japan from those in other countries, such as the ability to check and fit the local building codes and standards. The BIM software shown in Table 1 is commonly used in Japan.

3D printing is not commonly used in Japan during the design and construction planning phases to check and confirm 3D data as a real model except for by specific manufacturers and subcontractors. This situation may differ from the case in China or other countries.

\subsection{Case study in a large architectural firm}

The architectural firms in Japan can be divided into 2 categories: the majority are personal or small firm (atelier) 
Table 1 BIM software commonly used in Japan

\begin{tabular}{|c|c|c|c|c|c|}
\hline Discipline & BIM Software & Vendor & Area & BIM Software & Vendor \\
\hline Concept & TP-PLANNER & COMMUNICATION S. & Architectural & Revit Architecture & Autodesk \\
\hline \multirow{4}{*}{$\begin{array}{l}\text { Structural } \\
\text { analysis }\end{array}$} & SS3(SS7) & UNION SYSTEM & Design & ARCHICAD & Graphisoft \\
\hline & BUS-5 & KOZO SYSTEM & & GLOOBE & FUKUI COMPUTER \\
\hline & SEIN LA CREA & NTT-F & & Vectorworks & A\&A \\
\hline & BRAIN & TIS (Takenaka) & Building & CADWe'llTfas & DAITEC \\
\hline \multirow{3}{*}{$\begin{array}{l}\text { Structural } \\
\text { design }\end{array}$} & Revit Structure & Autodesk & Services & REBRO & NYK SYSTEMS \\
\hline & Tekla Structure & Tekla & & DesignDRAFT & SYSPRO \\
\hline & SIRCAD & Software Center & & CADEWA & Yondenko \\
\hline Steel & SkeleTON & CALTEC & Survey & HELIOS & Nisseki Survey \\
\hline Construction & $\begin{array}{l}\text { J-BIM Working } \\
\text { Drawing CAD }\end{array}$ & FUKUI COMPUTER & Environment & SAVE Architecture & Archi-pivot \\
\hline
\end{tabular}

offices, and there are a few large organizations. Among them, in the former category, BIM does not seem to be commonly used, except for by some distinctive architectural firms (e.g., Sherpa, known as OPEN BIM Café (http://openbimcafe.blogspot.jp/).

In the architectural firms of the latter category, BIM is utilized officially by collaborating with a BIM software house, such as Autodesk. For example, Nihon Sekkei takes advantage of BIM to obtain the benefits of time savings and the utilization of information, as shown in Table 2.

\subsection{Case study in a major general contractor}

\subsubsection{Role of general contractors in Japan}

In Japan, general contractors are expected to make shop drawings based on the drawings created by architects, and then they transfer the design information to specialty contractors. However, because the design information given by the architects tends to be insufficient, the general contractors in Japan create working drawings, such as a detail design of the plan and a detail design of the concrete structures, to provide the design information before they make the shop drawings. A significant portion of the construction projects in the private sector are under turnkey (design-build) contracts in Japan. Therefore, a number of projects are designed by the architects employed by general contractors. General contractors are trying to take advantage of BIM, assuming that they correspond to both design and construction.

\subsubsection{Case study in Obayashi Corporation (Nakajima, 2016)}

As a case study, Obayashi's initiatives are introduced below. Obayashi established a BIM promotion office in 2010, which was reassigned in 2013 to the Product Design Center, a specialized department for BIM. As BIM is a

Table 2 Case study in a large architectural firm (Iwamura, 2016)

Benefits of time savings

1) direct data transaction $\quad$ - Analysis of the sunshine and shade

- Data transaction with wind simulation

2) big data processing - High-performance computing at Autodesk's cloud supercomputer

- Large data processing, such as urban modeling

3) complex parameters $\quad$ - Study of a complex design with a 3D printer

4) beyond quantitative analysis

- Solve the gap between human impression and quantitative analysis, e.g., lighting design in an EV hall

Benefits of the utilization of information

1) exclusive output by BIM - Rooms in the plan painted with colors, auto-generated from the attributes of BIM

- Painted parts and elements can be integrated with a quantity survey

2) 3D BIM transaction

3) parametric design

- Capture the shape analyzed in a 3D modeling tool preserved to BIM

- Solid shape changed locally by controlling parameters

- Panel allocation is automatically calculated and optimized, reducing the number of curved panels

4) facility management

- Routine tasks can be automated by setting repeat workflows

e.g., Creating a perspective, integration of architectural and structural design (design of the dome, etc.)

- Reuse of the furniture data embedded in the design phase

- Determination of the specifications in the design phase 
modeling tool in $3 \mathrm{D}$, it is easier to match species among drawings and among specialty trades. General contractors and specialty contractors are able to communicate design information by looking at the same model. Therefore, "front loading" (advanced design review) is emphasized as an advantage, that is, a consistency adjustment from product design to development design can be implemented earlier.

3D scanners and 3D printers are used to improve the productivity of the design. There are limitations in 2D drawings. The means of the expression and communication of design information is changing by adopting BIM.

The architects and the manufacturer of the curtain wall collaborated in the construction of the exterior panels. The differences between the design documents and shop drawings were evaluated by checking the Excel data of the $3 \mathrm{D}$ shapes of the panels created by the architectural firm and the general contractor independently, without passing through a human check. The 3D model was transmitted through Rhinoceros (creation of free surface) and then Solidworks (3D CAD) to the NC machine. Obayashi calls this supply chain "From 3D (architect) to 3D (general contractor) to 3D (manufacturer)".

In collaboration with the steel fabricator, data processing was more efficient, as the conversion from the structural BIM Tekla to the production model by the fabricator was in CSV format, not IFC.

\section{History of research and development}

\subsection{Research on product model}

MLIT defines BIM as "to create computer 3D solid information as well as a building information model that has attribute information, such as the names and areas of rooms, specifications and performances of materials and components, and finishes" (The Ministry of Land, Infrastructure, Transport and Tourism, 2014).

These basic principles of BIM have been advocated in past research on product models since the beginning of 1990s. A product model is defined in JIS (Japanese Industrial Standards) B 3401: 1993 as "a model expressed inside a computer by describing the shape, features and other data of the product required in manufacturing the product". It had been recognized in building construction as a model to disassemble a building into elements and materials to manage the $3 \mathrm{D}$ information and attributes in integrated way.

It was also proposed in object-oriented analysis and design (Booch, 1994) in the early 1990s that classes and relations between classes can represent the entire configuration. Individual elements are defined as instances of the class. This is the same notation as for objects of the BIM. BIM can be valued in terms of implementing these concepts, but the ideas of research and development of BIM are not especially new or innovative. For example, the idea of "inheritance" to develop information plays an important role in object-oriented analysis and design, whereas "inheritance" has not been implemented fully in BIM. Therefore, in some cases, architects are obliged to input the attributes of the wall including detailed finishing, though it is even in the stage of sketch and esquisse. Such strange things may actually impede the free thinking of architects.

4.2 Development and failure of general integrated information systems

The Research Committee on Information Systems Technology in AIJ was originally established in June 1978 (120 year history of Architectual Institute of Japan, 2007). In the 1990s, integrated information systems for design and construction were developed by major general contractors, but the performance of computers was poor at that time. Thus, it took a large work load to input design information to the design department. The benefit for the construction site was not enough, so it could not be deployed in a company.

The Building Research Institute (a part of MLIT at that time) tried to develop a generic integrated information system for all of the general contractors, along with a policy to develop CALS/EC. They launched a project team calling on the representatives of major companies to settle on definitions of requirements, but failed to achieve a practical system design. Individually developed software by private companies, Auto CAD etc., has expanded its market share as a de facto standard, and the generic system lost the competition.

Major general contractors have developed their own BIM software and its family as a "standalone" system until now.

\subsection{On construction sites}

The mainstream of research and development mentioned above was mainly operated by system engineers or engineers in the design section. On the other hand, system development by construction site engineers has been found since approximately 1995. The latter was useful for general contractors because the purpose of development and application was clear, for example, a lifting plan (Yamamoto et al., 1996) or quantity survey (Sone et al., 2005).

It was quite difficult to share the benefits across the enterprise, even to the general contractor in turn-key 
(design-build) contracts, because the specifications requested for information systems by the design section and the construction section were different.

\section{Problems of BIM implementation in Japan}

\subsection{Barriers for BIM implementation in Japan}

\subsubsection{Official activities}

It seems that there is no stable roadmap for BIM implementation in Japan. In other words, as the construction market in Japan is so huge, the majority of industry watches the domestic market instead of the global one. Most of the BIMs adopted in major firms are closed within their own private supply chain, as if they are standing alone. They are not interested in generic and compatible BIMs involved with the global supply chain.

The official activities of BIM implementation vary for each firm. General contractors seem to hesitate to take advantage of BIM. For example, it depends on whether the boss of the section understands the advantage of BIM implementation.

\subsubsection{BIM Manager in Japan}

The definition of the BIM Manager is not clear in Japan. The authors understand that the expected role of the BIM
Manager is shown in Fig. 5. If the lead architect does not coordinate the design documents adequately, the design information will not be tightly integrated before being sent to regulatory submission. Unless it is rejected by the administrative office, it will be sent to the general contractor without consistency. Even in such cases, the role of the BIM Manager is to coordinate the design documents and to integrate them into the BIM. The position and the skill of the BIM Manager are different in each firm. The majority of BIM Managers in Japan are often just messengers among architects and engineers. They often have to develop their skills on their own. The BIM Manager has little rights or responsibilities.

\subsubsection{Clients in Japan}

Most of the clients of buildings in Japan do not have the experience to realize the benefits of BIM. Generally, they do not request to adopt BIM in the design contract or in the design-build contract. Therefore, it cannot be expected that the additional cost to adopt BIM is to be covered by the client. The architects and the general contractors have to demonstrate a project cost reduction if they adopt BIM in the project.

BIM implementation is not only to practice design in 3D but also to build a database of elements. However, the majority of architectural firms in Japan do not seem to have enough financial or human resources to face the "Front Loading" brought by BIM.

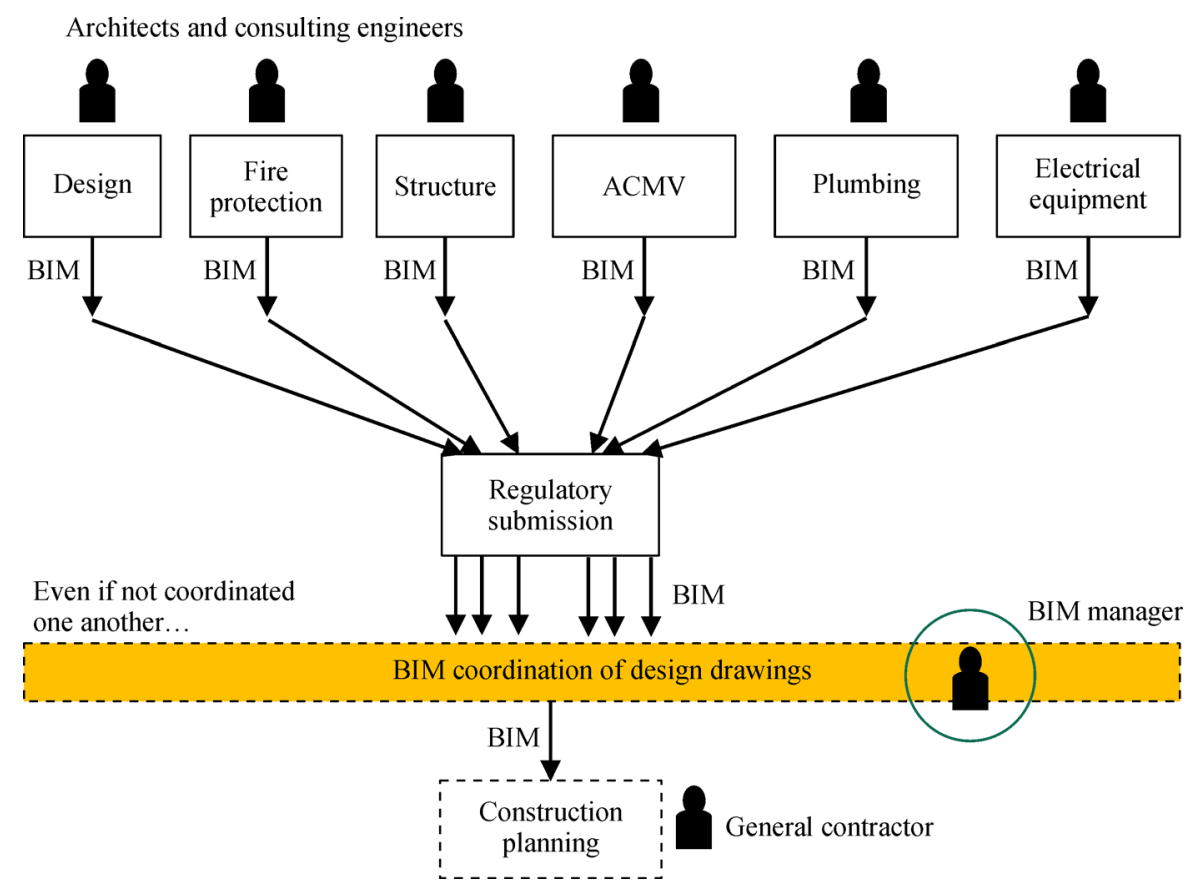

Fig. 5 Status and role of the BIM Manager 


\subsection{Problems of construction industry in Japan}

The problems of the construction industry in Japan should be recognized when BIM implementation is discussed.

\subsubsection{Drawing by general contractors}

As described above, general contractors in Japan draw or fulfill the design documents as well as shop drawings. In other countries, such as China, Singapore and the UK, general contractors do not draw the design documents. This is because of the ability and responsibility with respect to the design documents. Unpermitted design changes by general contractors frequently cost so much in penalties. Clients in the UK or US have tried to introduce Integrated Project Delivery (IPD) to invite the construction team to collaborate with the design team earlier to make the most effective decisions under the partnering agreement.

\subsubsection{Delay of decision making by clients and architects}

Client and architects can reduce the project risk related to design and drawings by transferring the risk to the general contractors because general contractors in Japan have enough ability to draw design documents. Thus, clients and architects in Japan are not sensitive to the schedule of decision making during the project process. They have no incentive to introduce BIM because the front loading and integrated project delivery caused by BIM will make their loads larger in the earlier stage of the project. However, "Front Loading" with BIM will be a good common policy to encourage earlier decision making by clients and architects to improve the situation.

\subsubsection{Productivity improvement in the 2 nd stage}

Productivity improvement in the Japanese construction industry was a hot topic in the 1980 s with respect to the schedule recovery from delays caused by troubles with stakeholders surrounding the construction site. In China, not highly skilled migrant workers are a problem in the improvement of productivity. In Singapore, the government has placed an emphasis on a policy to improve productivity by reducing the number of foreign workers. They are similar challenges as for the productivity improvement.

There is already no room to improve the productivity in Japanese construction industry. However, now skilled workers are leaving the industry, which presents difficulty in maintaining productivity and quality assurance in Japan. This phenomenon may be called "Productivity improvement in the 2nd stage". In Japan, it is logical to adopt BIM with standardization and simplification of design due to low-skill workers, if we are still trying to improve productivity. However, the process is behind those of China and Singapore.

There are different significances and backgrounds of the productivity improvement among China, Singapore and Japan, but it is actually the same challenges.

\section{Direction of research and development}

\subsection{Strategy of research and development}

\subsubsection{General contractors}

BIM implementation in design section provides an advantage for general contractors because it simplifies the tasks in projects under turn-key contracts. For example, general contractors desire to reduce complex interference checks by hand, even if BIM may increase the design loads on input information. The presence of general contractors will be increased with BIM implementation in the medium to long term.

\subsubsection{Architectural firms}

What type of a world of design activities can be created with BIM by architectural firms? Instead of using BIM as just a 3D drawing tool, it is expected that BIM can be adopted for creative design by utilizing its overwhelming ability of numerical analysis.

\subsubsection{Clients}

What are the benefits for clients in using BIM in the construction projects? Clients should obtain the benefit of BIM by improving the work process for earlier decision making. Architects and general contractors have to explain more specifically to clients the benefits of BIM.

\subsection{Areas for BIM implementation}

\subsubsection{Quantity surveying}

Data integration between BIM and quantity surveying is already practiced now, but its speed is still not satisfactory. Improved processing speed will be expected if the intermediate files in IFC format can be omitted. Quantity surveying software that can engage in direct data transaction with the BIM should be developed and improved. The inputs in the quantity surveying software should reflect the original BIM. It is requested to be available in the simulation at the rough estimation stage. 


\subsubsection{Construction}

There is also a problem in the data processing speed in the collaboration between BIM and construction. Even if architects provide a perfect BIM to general contractors, the information stored there tends to be unnecessary for the specialty contractors. A BIM that can easily generate only the parts necessary for the construction is required.

"Guideline for Collaboration between General Contractors and Subcontractors" was published by the Japan Federation of Construction Contractors in 2014, as shown in Fig. 6.

\subsubsection{Facility management}

The leading clients in Japan have shown interest in BIM in anticipation of using BIM in facility management. Case studies of facilities management in universities and factories have been already reported. BIM for only the completion of design documents is not the goal; the operational situation of buildings should also be reflected and added to the BIM. In addition, tools for simple input by $3 \mathrm{D}$ scanning existing buildings into BIM are required.

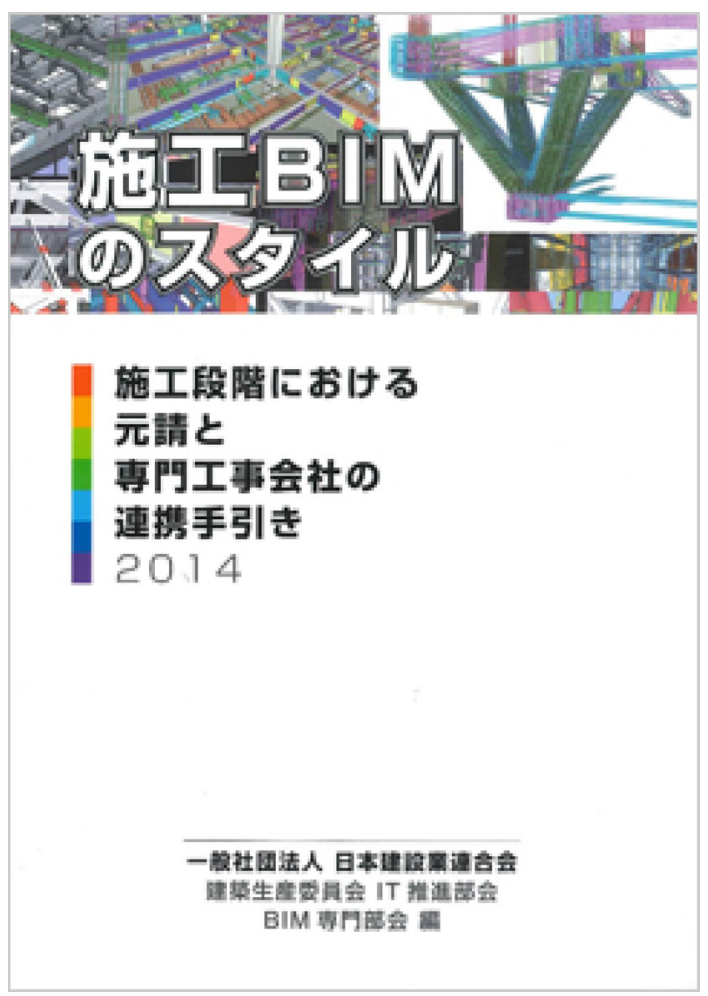

Fig. 6 Guideline for Collaboration between General Contractors and Subcontractors (http://www.nikkenren.com/publication/detail. html?ci $=200$ )

\section{Conclusions}

This paper described BIM implementation and indicated the barriers associated with BIM in Japan. BIM implementation in Japan is not always encouraged by board members in architectural firms and general contractors, as clients of the projects are not aware of the value and incentive to incorporate BIM use into the contracts of the projects.

The authors discussed the problems in project management to show the strategy of BIM implementation. General contractors in Japan have the ability to produce and coordinate design drawings and shop drawings with inhouse architects and engineers. Thus, the client and architects can reduce the project risk in design and drawings only if they transfer them to the general contractor. They are not always responsible for the schedule of decision making in the project process and have no incentive to introduce BIM.

The BIMs developed and customized by major general contractors exist as stand-alone software. They are within closed supply chains and not open to the global market. This sometimes presents a barrier to the general movement to promote BIM implementation in Japan.

It can thus be concluded that BIM is still in the process of helping stakeholders reduce risk and uncertainty. However, the authors predict that there is also space for innovation by excellent general contractors, and the authors will propose a strategy for new businesses to manage projects utilizing BIM.

Acknowledgements All of the people and institutions that contributed to the survey are gratefully acknowledged. This research is supported by the Japan Society for the Promotion of Science (JSPS) Grants-in-Aid for Scientific Research, Challenging Exploratory Research 26630271. The authors also would like to express gratitude to Mr. Nobuyuki Ikushima, President of Nisseki Survey, for his valuable advice and information.

\section{References}

Booch G (1994). Object-oriented Analysis and Design with Applications. San Francisco: Benjamin/Cummings Publishing Company

Government Building Department (2014a). Utilizing BIM in Public Building Projects. http://www.mlit.go.jp/gobuild/gobuild_tk6_ 000094.html

Government Building Department (2014b). BIM Pilot Project "Shinjuku Labors Federal Office Building". http:/www.mlit.go.jp/gobuild/ gobuild_tk6_000096.html

Government Building Department (2014c). BIM Pilot Project "Shizuoka Regional Legal Office Fujieda Branch". http://www.mlit.go.jp/ gobuild/gobuild_tk6_000098.html

Government Building Department (2014d). BIM Pilot Project "Maebashi Regional Federal Office Building". http://www.mlit.go.jp/ gobuild/gobuild_tk6_000099.html

Iwamura M (2016). BIM changes architecture. In: Nikkei Architecture 
Journal 40 Anniversary Symposium. Tokyo, 2016-5-20

120 year history of Architectural Institute of China. Journal of Architecture and Building Science, 122:1556

Nakajima J (2016). Where BIM is going now? Kansai Chapter meeting lecture, Construction Management Association of Japan, Osaka

Sone H, Nagao M, Toma K, Fujii H, Tsunakawa T, Matsuba H, Kayashima T (2005). Cost estimate and possibility of cost control due to production design using $3 \mathrm{D}-\mathrm{CAD}$ in production design. In: Proceedings of 20th Symposium on Building Construction and Management of Projects, Architectural Institute of Japan, 333-338 (in Japanese)

The Ministry of Land Infrastructure, Transport and Tourism (2014). Drawing up BIM Guideline and putting it in effect. http://www.mlit. go.jp/report/press/eizen06_hh_000019.html

Yamamoto N, Sawada T, Imanishi K, Watanabe M, Watanabe J, Ueno S (1996). Development of material transportation managing system - a management of material transportation using personal computer. In: Proceedings of 12th Symposium on Organization and Management of Building Construction, Architectural Institute of Japan, 233-238 (in Japanese) 